\title{
Wisdom of Crowds reveals decline of Asian horseshoe crabs in Beibu Gulf, China
}

\author{
Yongyan Liao, Hwey-Lian Hien, Shuqing Xu, Qiuping Zhong \\ Juan Lei, Mingzhong Liang, Huaiyi Fang, Lili Xu, Wuying Lin \\ Xiaobo Xiao, Chang-Po Chen, Siu Gin Cheung and Billy K. Y. Khan
}

\begin{abstract}
Population decline among Asian horseshoe crabs in Asia is increasingly reported, but knowledge of their population and ecological status in China is limited. We conducted community interviews in 30 fishing villages around Beibu Gulf in Guangxi, China, to collect distribution information about the potential spawning/nursery grounds of Tachypleus tridentatus and Carcinoscorpius rotundicauda, and any imminent threats to their populations. Based on the results from 400 respondents we identified 45 potential spawning/nursery grounds distributed widely along the shores of Beibu Gulf. We visited 10 of these sites and verified the presence of juvenile horseshoe crabs by field surveys. Nearly all respondents reported an overall depletion in horseshoe crab populations from these 45 sites, which they attributed mainly to unsustainable fishing practices. Respondents who reported having seen horseshoe crab mating pairs on shores were mostly older people, which may suggest a considerable reduction in horseshoe crabs coming to the shores to spawn in recent years. The mean daily harvest of adult $T$. tridentatus offshore, as indicated by fishers, has declined from c. 50-1,000 in the 1990s to o-30 individuals during 2011-2016. Our Wisdom of Crowds approach, supported by confirmatory field surveys, is a cost-effective method for assessing the population status of horseshoe crabs, and the level of threat they face. Similar approaches with other species are likely to be particularly valuable in the Asia-Pacific region, where well-structured population monitoring is largely unaffordable.
\end{abstract}

Keywords Beibu Gulf, Carcinoscorpius rotundicauda, data deficient, horseshoe crabs, local ecological knowledge, mating pairs, Tachypleus tridentatus

\footnotetext{
Yongyan LiaO ${ }^{*}$ and Billy K. Y. Kwan* (Corresponding author) Guangxi Key Laboratory of Beibu Gulf Marine Biodiversity Conservation, Qinzhou University, People’s Republic of China. E-mail kityuekwan@qzhu.edu.cn

Hwey-Lian Hsien and Chang-Po Chen Biodiversity Research Center, Academia Sinica, Taipei, Taiwan

Shuqing Xu, Qiuping Zhong, Juan Lei, Mingzhong Liang, Huaiyi Fang and Lili Xu Ocean College of Qinzhou University, People's Republic of China

Wuying Lin and XIAOBo XIAO Guangxi Biodiversity Research and Conservation Association, People's Republic of China

SiU Gin Cheung Department of Biology and Chemistry, City University of Hong Kong, Hong Kong

*Also at: Ocean College of Qinzhou University, People's Republic of China

Received 6 April 2017. Revision requested 24 May 2017.

Accepted 24 July 2017. First published online 7 November 2017.
}

Supplementary material for this article can be found at https://doi.org/10.1017/So03060531700117X

\section{Introduction}

ecording changes in population status and identifying - anthropogenic factors responsible for species declines are fundamental for evaluating potential risks to biodiversity and developing effective conservation management actions (Segan et al., 2011; Turvey et al., 2013; Bland et al., 2017). However, it can be difficult to obtain direct information on such parameters for species of conservation concern, particularly in geographical regions that have large human populations but little focus on formal scientific research or monitoring of exploitation (Turvey et al., 2015). One such case is the limited population research conducted on the Chinese horseshoe crab Tachypleus tridentatus and mangrove horseshoe crab Carcinoscorpius rotundicauda in China, despite China being largely responsible for driving the recent decline in horseshoe crab populations across Asia (Liao \& Li, 2001; Weng et al., 2012; Gauvry, 2015). Tachypleus tridentatus occurs in the Seto Inland Sea of Japan, along the coast of China, and southwards to Borneo and Sumatra in Indonesia, whereas C. rotundicauda is commonly recorded in Indonesia, Malaysia, Singapore, the Philippines, Thailand, Cambodia, Vietnam and the Bay of Bengal in India (Sekiguchi, 1988). Horseshoe crabs are ecologically important in coastal ecosystems, serving as both prey and predators, hosts for epibionts, and bioturbators for sediment-water nutrient exchanges (Botton et al., 2003; Botton, 2009). They also have high commercial value in the manufacture of Tachypleus amoebocyte lysate, which is used in the testing of bacterial contamination in biomedical products (Walls et al., 2002; Gauvry, 2015). Despite being listed as Key Protected Aquatic Wildlife in four provinces of China, T. tridentatus populations are heavily exploited to meet the increasingly high demands for Tachypleus amoebocyte lysate production and local food consumption (Liao et al., 2001; Hong, 2011; Gauvry, 2015). Other factors contributing to the depletion of horseshoe crab populations include the destruction of their spawning shores as a result of coastal reclamation, and marine pollution, as reported in Taiwan (Hsieh \& Chen, 2015), Hong Kong (Kwan et al., 2016) and Japan (Seino et al., 2003). Carcinoscorpius rotundicauda 
populations in Hong Kong and Singapore are also decreasing, mainly as a result of the loss of mangrove and mudflat habitats (Shin et al., 2009; Cartwright-Taylor et al., 2011).

Tachypleus tridentatus and C. rotundicauda are currently categorized as Data Deficient on the IUCN Red List (WCMC, 1996a,b), but based on the available evidence it is likely that their populations will decline further because their protection is a low priority for local governments (Bland et al., 2017). In general, public awareness of the conservation of marine invertebrates is low (Cardoso et al., 2011). There is an urgent need for up-to-date information on the distribution and population trends of Asian horseshoe crabs in China, and the threats they face, to protect remaining populations across their distribution range. To this end, a broad approach that facilitates rapid, inexpensive and wide-scale collection of population data must be developed. An important means of addressing information gaps regarding species conservation and management, especially in data-poor situations, is the collection of local knowledge (Segan et al., 2011; Nash et al., 2016; Pan et al., 2016). This so-called Wisdom of Crowds technique is based on a mechanism that aggregates knowledge of a large sample population to generate quantitative estimates and spatial reasoning (Whitmore, 2016). Although the application of this method is relatively new, the merits of the approach, including its independence, diversity of opinion, decentralization and aggregation, are recognized as of value for informing natural resource management and conservation (Surowiecki, 2004; Arlinghaus \& Krause, 2013). Previous studies have found that fishers' perceptions about population trends matched scientific data reasonably well in some circumstances (Rochet et al., 2008; Daw et al., 2011; Arlinghaus \& Krause, 2013). In the case of Asian horseshoe crabs, local community members, especially fishers, may be able to report the historical and recent status of a species as well as underlying drivers of species decline (sensu Ainsworth et al., 2008).

We conducted a study in three coastal cities along Beibu Gulf in south-western China to obtain data on the potential distribution of spawning/nursery grounds of $T$. tridentatus and C. rotundicauda, and anthropogenic threats to the populations, through community interviews. Beibu Gulf is considered to be the most critical spawning/nursery ground for Asian horseshoe crab populations, particularly T. tridentatus (Hu et al., 2009; Li, 2010). We verified our findings on the distribution of the two species by surveys of intertidal habitats for juvenile populations. Such findings can strengthen our understanding of the extent to which local knowledge can assist in the conservation of Asian horseshoe crabs in locations where these species are under intense anthropogenic pressure.

\section{Study area}

Community interviews were conducted during 19 September-1 October 2015 in 30 fishing villages and small towns around the three coastal cities (Fangchenggang, Qinzhou and Beihai) along Beibu Gulf in Guangxi Zhuang Autonomous Region, China (Table 1). Beibu Gulf is a semi-closed gulf located in the northern South China Sea between China and Vietnam. The Gulf is $330 \mathrm{~km}$ wide at its widest and has a total area of $128,000 \mathrm{~km}^{2}$ (Chen et al., 2009). It has extensive estuarine ecosystems, with considerable freshwater input from seven major rivers (Fangcheng, Qin, Dafeng, Nanliu, Red, Beilun, Changhua; Chen et al., 1991). The rivers carry a significant load of nutrients from the land, which are essential for phytoplankton growth, which in turn supports the rich biodiversity and productive fisheries in the northern South China Sea (Yu \& Mu, 2006).

Both $T$. tridentatus and C. rotundicauda are recorded frequently in mangrove-dominated estuaries with patchy seagrass beds and extensive sandy mudflats along the coastline of Beibu Gulf (Hu et al., 2009; Chen et al., 2015). In general, horseshoe crabs require three types of coastal habitats during their entire life cycle: adults nest on open, sandy beaches near the high water mark or along the edge of mangrove forests, juveniles forage and grow within the intertidal zones of the same shores or their adjacent flats, and subadults and adults inhabit shallow subtidal areas (Chen et al., 2015; Smith et al., 2017). During the spawning season local people encounter adult $C$. rotundicauda mating pairs in amplexus burrowing in the mud along the edges of mangrove forests. Mating pairs of $T$. tridentatus are occasionally entangled in fishing nets cast along the coastline to harvest fish when the tide recedes.

\section{Methods}

The 30 villages and towns were chosen for the interviews because sightings of horseshoe crabs on the beaches nearby had been reported in the grey literature. Respondents were intercepted at random as the survey party walked through each village. We aimed to survey people of both sexes and of various ages, to capture potentially diverse knowledge and experience of horseshoe crabs across the sampling locations. Only one person per household was surveyed, to minimize the chance of double counting the same information from various family members. We interviewed 400 people in total, and the number of respondents from each village varied (4-27 individuals), depending on people's willingness to participate in the interviews. Interview methods followed the guidelines of the American Sociological Association, including informing all respondents at the outset about the study's general aims, assuring them that the data would be anonymized, and conducting the interviews only after participants had given verbal consent. Interviews were conducted by research team members and student helpers, all of whom were native Mandarin Chinese speakers. There was also at least one team member present during each 
TABLE 1 Villages and towns along the shores of Beibu Gulf in Guangxi Zhuang Autonomous Region, China (Fig. 1), where interview surveys were conducted to gather local knowledge about the Asian horseshoe crabs Tachypleus tridentatus and Carcinoscorpius rotundicauda, with the number of responses collected at each location.

\begin{tabular}{|c|c|}
\hline Village name (by area) & No. of responses \\
\hline \multicolumn{2}{|l|}{ Fangchenggang West } \\
\hline Zhushan & 11 \\
\hline Wutou & 11 \\
\hline Banai & 9 \\
\hline Jiaodong & 24 \\
\hline Shijiao & 27 \\
\hline Xinji & 25 \\
\hline Wanwei & 9 \\
\hline \multicolumn{2}{|l|}{ Fangchenggang East } \\
\hline Shankuaishi & 13 \\
\hline Niutou & 18 \\
\hline Yuzhouping & 10 \\
\hline Zhouwei & 10 \\
\hline Qisha & 13 \\
\hline Leshan & 15 \\
\hline Shaluoliao & 17 \\
\hline \multicolumn{2}{|l|}{ Qinzhou } \\
\hline Longmengang & 22 \\
\hline Maoling & 20 \\
\hline Kangxiling & 6 \\
\hline Dahuan & 20 \\
\hline Shajiao & 19 \\
\hline Paotai & 20 \\
\hline \multicolumn{2}{|l|}{ Beihai West } \\
\hline Zhakou & 4 \\
\hline Beihai Pier & 4 \\
\hline Zhulinyanchang & 5 \\
\hline \multicolumn{2}{|l|}{ Beihai East } \\
\hline Baishatou & 16 \\
\hline Pangxietian & 17 \\
\hline Chongmei & 4 \\
\hline Dabudun & 8 \\
\hline Hongkan & 11 \\
\hline Shankou & 6 \\
\hline Shatian & 6 \\
\hline
\end{tabular}

visit who could speak local dialects. All respondents were interviewed one-to-one using a standard anonymous questionnaire in simplified Chinese characters, containing descriptive and multiple-choice questions in three sections: present occurrences, population trends and threats, and fishing activities targeted at horseshoe crabs (Supplementary Material). Respondents could choose more than one answer for questions regarding the horseshoe crab species observed, perceived causes of the population decline, and fishing methods used for harvesting adult crabs (Supplementary Material). To improve the accuracy of the information collected, responses were included in the analysis only if the respondent had seen a horseshoe crab in the wild. The respondents who could not read or write in simplified
Chinese were assisted by the researchers through oral communication in either Mandarin Chinese or native dialects.

As horseshoe crabs may utilize sandy mudflats as their spawning and/or nursery grounds, the potential shores indicated by the respondents were considered to be a mixture of spawning and nursery grounds. Based on the information provided by the respondents, and given budget constraints, a total of 1o potential spawning/nursery shores were chosen at random and verified by field surveys conducted at each site in March and June 2016. The sites were chosen to cover at least two potential spawning/nursery grounds from each of the three coastal cities in Beibu Gulf. In Southern China, summer is the best season to conduct juvenile population surveys, as the crabs feed actively in the intertidal habitats after prolonged hibernation in winter and early spring (Chiu \& Morton, 2004; Hu et al., 2009). During each field visit a team of five trained researchers walked at random and searched for juveniles within the intertidal area, 1.6-2.0 $\mathrm{m}$ above chart datum (i.e. the lowest astronomical tide as defined by the UK Hydrographic Office) for 120 minutes. The total monitoring area for each shore was $62,300-77,100 \mathrm{~m}^{2}$. Juvenile $T$. tridentatus were distinguished from $C$. rotundicauda by the triangular cross section of their telson, as well as the presence of three distinct immovable spines above the telson insertion and three spines growing along the central ridge on the dorsum of the opisthosomal carapace (Chen et al., 2015; Hu et al., 2015).

Statistical analysis was performed using SPSS v. 16.0 (SPSS, Inc., Chicago, USA), after data had been checked for normality and homogeneity of variance using the Shapiro-Wilk and Levene's tests, respectively. If these tests failed, data were logarithmically transformed. An independent samples $t$-test was applied to analyse the difference in the age of respondents who had or had not observed mating pairs of horseshoe crabs on shores, and who had or had not eaten adult $T$. tridentatus before.

\section{Results}

We interviewed 325 men and 75 women, with a mean age of $53.3 \pm$ SD 16.2 years (range 15-99). According to their responses, juvenile and/or mating pairs of horseshoe crabs had been observed at a total of 45 sites (Fig. 1a). Field monitoring confirmed the presence of juvenile T. tridentatus and/or C. rotundicauda at all 10 of the sites selected for monitoring (Fig. 1b). These sites were previously believed to be spawning/nursery grounds for T. tridentatus only; however, juvenile $C$. rotundicauda were recorded at five of the sites, along with juvenile $T$. tridentatus (Fig. 1a, b). This may reflect the difficulty for non-experts of distinguishing juvenile $C$. rotundicauda from $T$. tridentatus. Only T. tridentatus were found at Zhakou, and only C. rotundicauda were found at Shankou during the two field 


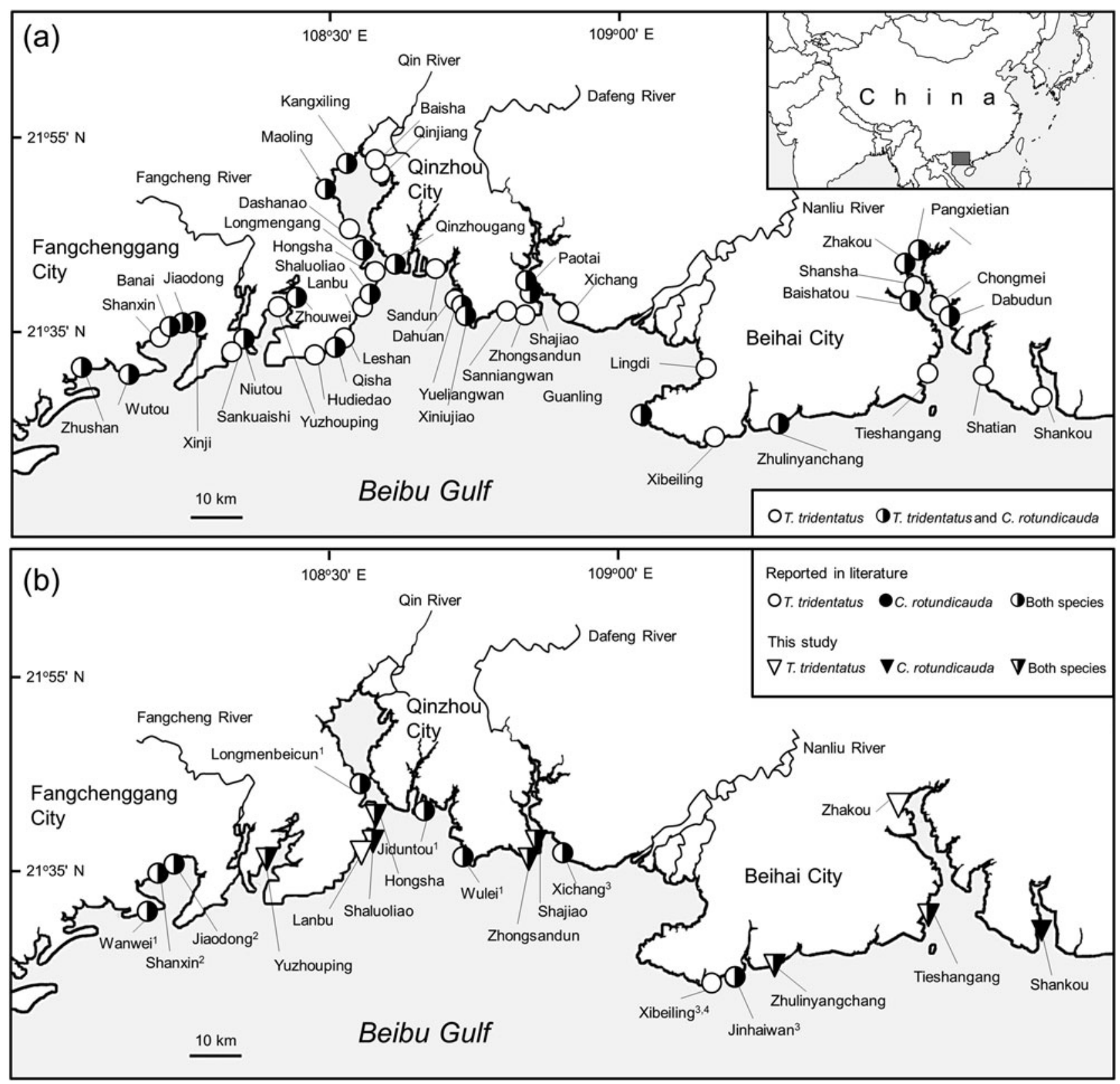

FIG. 1 (a) Locations of potential spawning/nursery grounds of the Asian horseshoe crabs Tachypleus tridentatus and Carcinoscorpius rotundicauda in Beibu Gulf, Guangxi, China, as indicated by interviews with local people in 30 villages and towns along the coast, and (b) locations of spawning/nursery grounds of T. tridentatus and C. rotundicauda reported in the literature (1, Liang, 1985; 2, Chen et al., 2015; 3, Hu et al., 2015; 4, Hu et al., 2009) and confirmed by field monitoring in this study.

visits (Fig. 1b). Considering our findings along with the previously published population data (Liang, 1985; Hu et al., 2009, 2015; Chen et al., 2015), there are 19 known nursery sites for juvenile Asian horseshoe crabs in Beibu Gulf (Fig. 1b). This is a conservative number, as more spawning/nursery grounds may be confirmed by field surveys. Respondents who had seen a mating pair of horseshoe crabs on the shore were significantly older $(59.9 \pm$ SD 13.7 years) than those who had not $(48.0 \pm$ SD 16.2 years; $\mathrm{df}=329, t=7.172, \mathrm{P}=0.000)$. Ninety-five percent of the respondents agreed that there had been a population decline among horseshoe crabs in Beibu Gulf in the previous 5 years, $3.4 \%$ stated that the population had increased, and $1.6 \%$ did not perceive any obvious change (Fig. 2a). Only one respondent could provide a specific location where there had potentially been an increase in the population.

Respondents attributed the decline of horseshoe crabs to overharvesting $(75.8 \%)$, followed by industrial pollution (28.6\%) and coastal reclamation (16.1\%; Fig. 2b). Mass harvesting of adult $T$. tridentatus had been witnessed by $74.1 \%$ of respondents $(\mathrm{n}=223)$. The methods used to catch horseshoe crabs included bottom trawling $(36.9 \%)$, gill-netting 
(a) Perceived population trend

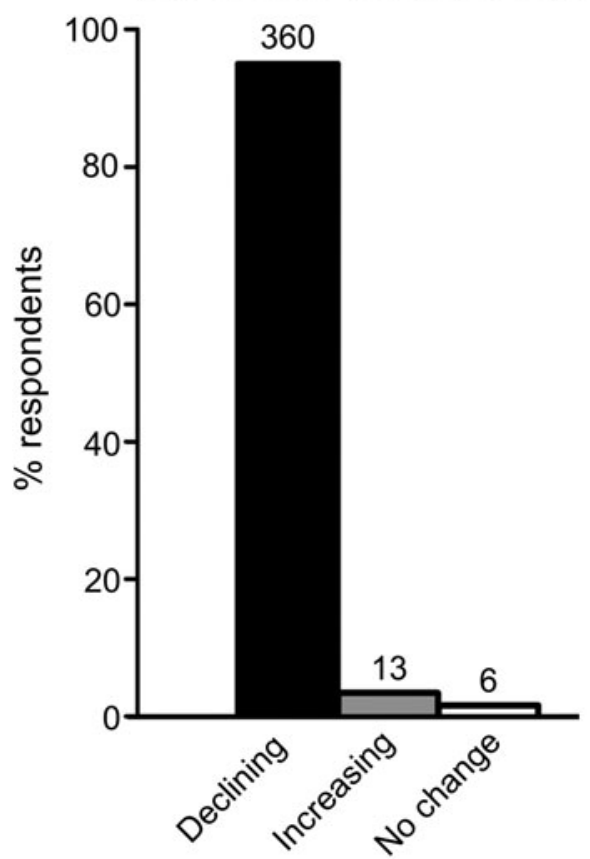

(b) Perceived cause of decline

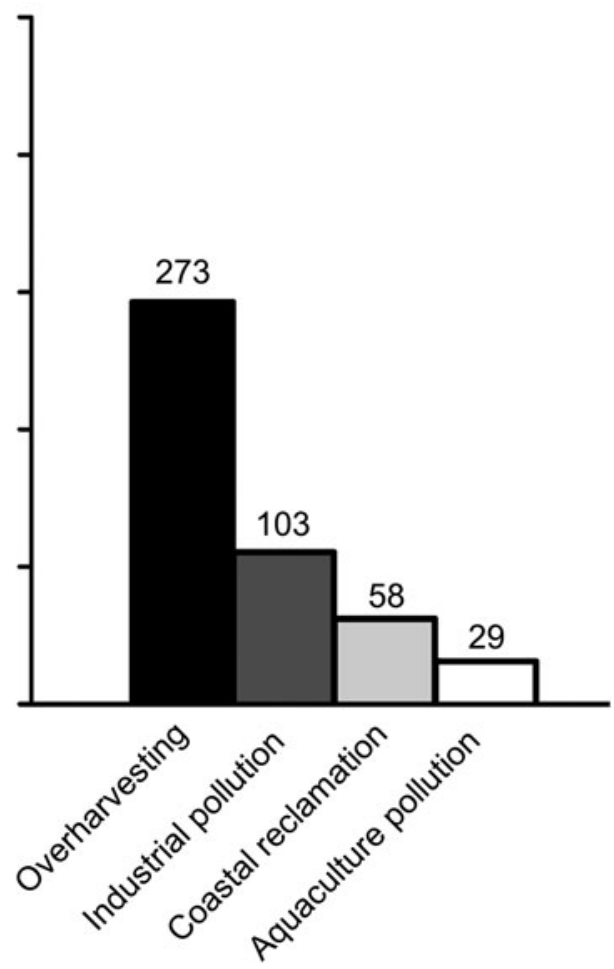

FIG. 2 (a) Respondents' perceptions of the population trend of adult horseshoe crabs in Beibu Gulf, China (Fig. 1), and (b) perceived causes of population decline. The number of responses is indicated above the bars.
(31.1\%) and purse-seine fishing (29.0\%). According to the respondents' observations, $69.9 \%$ of T. tridentatus harvested were adults or subadults (prosomal width $>10 \mathrm{~cm}$ ), and $23.8 \%$ were 1oth-instar or larger juveniles. The mean daily catch rate during 2011-2016 as estimated by the interviewees was o-30 individuals ( $\mathrm{n}=144$ respondents), which was significantly lower compared to the mean catch rate in the 1990 s, which was $50-1,000$ individuals per day $(n=35)$. Respondents reported that the consumption of adult T. tridentatus was common practice $(95.2 \% ; \mathrm{n}=378)$. The majority $(96 \% ; \mathrm{n}=382)$ considered $T$. tridentatus to be edible, although $71 \%(n=115)$ had heard of food-poisoning incidents caused by other horseshoe crab species. There was no statistical difference between the age of respondents who habitually ate horseshoe crabs and those who did not $(\mathrm{df}=385, t=-0.122, \mathrm{P}=0.903)$.

\section{Discussion}

In mainland China horseshoe crabs occur in the south of the Yangtze River Delta, along the coastline of Shanghai, Fuzhou, Xiamen and Shantou Cities, and southwards to Leizhou, Beibu Gulf and Hainan Island (Liao et al., 2001). Beibu Gulf is believed to accommodate the highest density of $T$. tridentatus globally (Liao \& Li, 2001; Brockmann \& Smith, 2009; Weng et al., 2012). According to the grey literature and other information sources, Asian horseshoe crabs were probably distributed extensively over all mudflats, beaches and shallow waters in Beibu Gulf at least until the 199os. In the 1980s T. tridentatus production could reach 0.4-1.4 million individuals per year (Liang, 1985; Liao \& $\mathrm{Li}, 2001$ ). Despite the species' unusually high occurrence in Beibu Gulf, information about its abundance and distribution is limited. The first quantitative data on the daily harvest of T. tridentatus and C. rotundicauda on five shores within Beibu Gulf were reported in 1985 (3-7 pairs; Liang, 1985). During 2008-2009, Hu et al. (2015) discovered three previously unknown nursery grounds of $T$. tridentatus and C. rotundicauda (Fig. 1b), with a juvenile density of o.883.19 individuals per $100 \mathrm{~m}^{2}$. Chen et al. (2015) found two more new nursery grounds on the west coast of Beibu Gulf, and recorded a juvenile density of $0.02-0.25$ individuals per $100 \mathrm{~m}^{2}$. By gathering local knowledge from 30 fishing communities, we identified 45 potential spawning/ nursery grounds, distributed widely along the shores of Beibu Gulf, 10 of which were confirmed by surveys. This suggests that local knowledge is useful and effective in identifying potential habitats for juvenile T. tridentatus and C. rotundicauda.

Previous studies have reported declining trends in populations of Asian horseshoe crabs along the coastline of Zhejiang, Fujian, Guangdong, Guangxi and Hainan provinces (Liao \& Ye, 2000; $\mathrm{Li} \& \mathrm{Hu}, 2011$; Weng et al., 2012). It is estimated at least a million pairs of adult T. tridentatus are exploited each year to satisfy the demand for consumption and biomedical applications (Liao \& Ye, 2000; Li \& Hu, 2011), and these are mainly imported from Vietnam. Such 
intense harvesting pressure in addition to habitat destruction may have driven horseshoe crab populations to the edge of extinction. Our interview results indicated that the horseshoe crab population in Beibu Gulf has declined substantially: (1) nearly all interviewees reported an overall reduction in the abundance of horseshoe crabs in the previous 5 years; (2) older respondents were more likely to have seen horseshoe crab mating pairs on the shores than younger respondents; and (3) the respondents reported a mean daily catch rate of $0-30$ adult $T$. tridentatus, which is a significant decline compared with 50-1,000 individuals per day in the 1990s. The reduction in population abundance was attributed mainly to unsustainable fishing practices. Our findings are consistent with previous reports of $T$. tridentatus decline (Liao \& Li, 2001; Huang et al., 2003; Weng et al., 2012), and indicated that most people in the region, regardless of their age, consumed adult $T$. tridentatus, despite the species being listed as Key Protected Aquatic Wildlife in Guangxi province. In general, local people avoid consuming adult C. rotundicauda and unlaid eggs, following reports of food poisoning caused by the presence of saxitoxin and tetrodotoxin (Shumway, 1995; Liao et al., 2012). However, the cultural norm of consuming horseshoe crab as a delicacy may impede efforts to motivate local communities to conserve the remaining $T$. tridentatus population in Beibu Gulf. Long-term and local-based conservation education programmes (e.g. raising laboratory-cultured juvenile horseshoe crabs at secondary schools, as described by Kwan et al., 2017) are useful in promoting positive changes in students' behaviour and attitudes towards horseshoe crab conservation. Such participatory educational activities, supported by public awareness programmes, could have a significant influence in deterring local communities from eating horseshoe crabs.

As the problems of increasing human disturbance and overharvesting are expected to persist, there is an immediate need for a management strategy for T. tridentatus conservation. At the 2012 IUCN World Conservation Congress, a motion for the conservation of Asian horseshoe crabs was passed unanimously, with a recommendation encouraging members to identify critical habitats and to protect them using appropriate integrated marine and coastal management approaches (IUCN, 2012). However, territory-wide distribution surveys of Asian horseshoe crabs in China would be costly and require significant effort, particularly given limited baseline data. Gathering local knowledge could be of particular use in countries or areas where conservation budgets are insufficient to support well-structured quantitative monitoring (Whitmore, 2016). Follow-up confirmatory field surveys, as described here, have the potential to attract funding for further studies. Given that both T. tridentatus and C. rotundicauda are categorized as Data Deficient, the Wisdom of Crowds method could be used to collect data and facilitate assessment of the species' conservation status. Fishing communities identified the possible extent of occurrence for both species, which are distributed widely along the shores of Beibu Gulf. However, despite their widespread occurrence, there is a perception among fishers that horseshoe crab populations are in decline, based on their direct observations of mating pairs on the shores, and the catch rate of adult T. tridentatus offshore. The causes of the decline, including unsustainable fishing, industrial pollution and coastal reclamation, may be irreversible, and the available evidence should be sufficient to urge the provincial Chinese authorities to implement management conservation actions, particularly to ensure sustainable use of horseshoe crab resources by fishers and the Tachypleus amoebocyte lysate industry. Other recommendations for local authorities include (1) reducing illegal trade of horseshoe crabs; (2) promoting establishment of protected areas for horseshoe crabs; (3) implementing effective management and restoration of breeding/nursery habitat; (4) strengthening research and conservation capacity; and (5) raising public awareness of horseshoe crab conservation. Regarding the increasing need for cheap and rapid population assessment tools, Wisdom of Crowds methods are an overlooked but potentially valuable tool for conservation, particularly in the Asia-Pacific region, where conventional field survey methods are largely unaffordable and human disturbance of horseshoe crab populations is intense.

\section{Acknowledgements}

This project was funded by the National Natural Science Foundation of China (41466003), Guangxi Natural Science Foundation (2015GXNSFDA139016), Guangxi Marine Science and Technology Fund (GXZC2015-G3-3692-GXJX), Guangxi Key Laboratory of Beibu Gulf Marine Biodiversity Conservation, Qinzhou University (2015ZAo2) and Guangxi Colleges and Universities Innovation Research Team. We are grateful to the students from the Ocean College of Qinzhou University for their assistance in conducting community interviews and field surveys.

\section{Author contributions}

YL led the research project, developed the overall research framework and methods, compiled and clustered data for analysis, and prepared the article. SX, QZ, JL, ML, HF, LX, $\mathrm{WL}$ and XX conducted community interviews and field population surveys. HLH and CPC provided input on local context to ensure the research framework and methods were relevant. SGC conducted statistical analysis and prepared the figures. BKYK supervised the research to ensure it met scientific requirements. HLH, CPC, SGC and 
BKYK reviewed and edited the article, which was read and approved by all authors.

\section{References}

Ainsworth, C.H., Pitcher, T.J. \& Rotinsulu, C. (2008) Evidence of fishery depletions and shifting cognitive baselines in Eastern Indonesia. Biological Conservation, 141, 848-859.

Arlinghaus, R. \& Krause, J. (2013) Wisdom of the crowd and natural resource management. Trends in Ecology \& Evolution, 28, 8-11.

Bland, L.M., Bielby, J., Kearney, S., Orme, C.D.L., Watson, J.E. \& Collen, B. (2017) Toward reassessing data-deficient species. Conservation Biology, 31, 531-539.

Botton, M.L. (2009) The ecological importance of horseshoe crabs in estuarine and coastal communities: a review and speculative summary. In Biology and Conservation of Horseshoe Crabs (eds J. T. Tanacredi, M.L. Botton \& D.R. Smith), pp. 45-63. Springer US, New York, USA.

Botton, M.L., Shuster, Jr, C.N. \& Keinath, J.A. (2003) Horseshoe crabs in a food web: who eats whom? In The American Horseshoe Crab (eds C.N. Shuster Jr, R.B. Barlow \& H.J. Brockmann), pp. 133-153. Harvard University Press, Cambridge, USA.

Brockmann, H.J. \& Smith, M.D. (2009) Reproductive competition and sexual selection in horseshoe crabs. In Biology and Conservation of Horseshoe Crabs (eds J.T. Tanacredi, M.L. Botton \& D.R. Smith), pp. 199-221. Springer US, New York, USA.

Cardoso, P., Borges, P.A.V., Triantis, K.A., Ferrández, M.A. \& Martín, J.L. (2011) Adapting the IUCN Red List criteria for invertebrates. Biological Conservation, 144, 2432-2440.

Cartwright-Taylor, L., Von Bing, Y., Chi, H.C. \& Tee, L.S. (2011) Distribution and abundance of horseshoe crabs Tachypleus gigas and Carcinoscorpius rotundicauda around the main island of Singapore. Aquatic Biology, 13, 127-136.

Chen, C.P., YAnG, M.C., FAn, L.F., Qiu, G.L., Liao, Y.Y. \& Hsieh, H. L. (2015) Co-occurrence of juvenile horseshoe crabs Tachypleus tridentatus and Carcinoscorpius rotundicauda in an estuarine bay, southwestern China. Aquatic Biology, 24, 117-126.

Chen, G., Gu, X. \& Gao, H. (1991) Marine Fishery Environment in China, 1st edition. Zhejiang Scientific and Technological Press, Hangzhou, China. [In Chinese, with English abstract]

Chen, Z., Xu, S., Qiu, Y., Lin, Z. \& Jia, X. (2009) Modeling the effects of fishery management and marine protected areas on the Beibu Gulf using spatial ecosystem simulation. Fisheries Research, 100, 222-229.

Chiu, H.M.C. \& Morton, B. (2004) The behaviour of juvenile horseshoe crabs, Tachypleus tridentatus (Xiphosura), on a nursery beach at Shui Hau Wan, Hong Kong. Hydrobiologia, 523, 29-35.

Daw, T.M., Robinson, J. \& Graham, N.A.J. (2011) Perceptions of trends in Seychelles artisanal trap fisheries: comparing catch monitoring, underwater visual census and fishers' knowledge. Environmental Conservation, 38, 75-88.

GAUVRY, G. (2015) Current horseshoe crab harvesting practices cannot support global demand for TAL/LAL: the pharmaceutical and medical device industries' role in the sustainability of horseshoe crabs. In Changing Global Perspectives on Horseshoe Crab Biology, Conservation and Management (eds R.H. Carmichael, M.L. Botton, P.K.S. Shin \& S.G. Cheung), pp. 475-482. Springer International Publishing, Cham, Switzerland.

Hong, S. (2011) Biology of Horseshoe Crabs, Tachypleus tridentatus, 1st edition. Xiamen University Press, Xiamen, China. [In Chinese]
Hsien, H.L. \& Chen, C.P. (2015) Current status of Tachypleus tridentatus in Taiwan for Red List assessment. In Changing Global Perspectives on Horseshoe Crab Biology, Conservation and Management (eds R.H. Carmichael, M.L. Botton, P.K.S. Shin \& S. G. Cheung), pp. 383-396. Springer International Publishing, Cham, Switzerland.

Hu, M., Kwan, B.K.Y., Wang, Y., Cheung, S.G. \& Shin, P.K.S. (2015) Population structure and growth of juvenile horseshoe crabs Tachypleus tridentatus and Carcinoscorpius rotundicauda (Xiphosura) in southern China. In Changing Global Perspectives on Horseshoe Crab Biology, Conservation and Management (eds R. H. Carmichael, M.L. Botton, P.K.S. Shin \& S.G. Cheung), pp. 167180. Springer International Publishing, Cham, Switzerland.

Hu, M., Wang, Y., Chen, Y., Cheung, S.G., Shin, P.K.S. \& Li, Q. (2009) Summer distribution and abundance of juvenile Chinese horseshoe crabs Tachypleus tridentatus along an intertidal zone in southern China. Aquatic Biology, 7, 107-112.

Huang, Q., Lin, N.F., Gao, Y.S., You, Y. \& LaI, X.X. (2003) The analysis of the reasons for the population decline of Chinese horseshoe crabs in Pingtan. Fujian Environment, 20, 7-8. [In Chinese, with English abstract]

IUCN (2012) Resolutions and Recommendations, 1st edition. IUCN, Gland, Switzerland.

Kwan, B.K.Y., Cheung, J.H.Y., Law, A.C.K., Cheung, S.G. \& Shin, P.K.S. (2017) Conservation education program for threatened Asian horseshoe crabs: a step towards reducing community apathy to environmental conservation. Journal for Nature Conservation, 35 , 53-65.

Kwan, B.K.Y., Hsieh, H.L., Cheung, S.G. \& Shin, P.K.S. (2016) Present population and habitat status of potentially threatened Asian horseshoe crabs Tachypleus tridentatus and Carcinoscorpius rotundicauda in Hong Kong: a proposal for marine protected areas. Biodiversity and Conservation, 25, 673-692.

LI, Q.Z. (2010) Advance on conservation of Chinese horseshoe crab (Tachypleus tridentatus). Journal of Biology, 27, 71-74. [In Chinese, with English abstract]

LI, Q.Z. \& Hu, M.H. (2011) Status of Chinese horseshoe crab population and conservation advance in Beihai, Guangxi. Marine Environmental Science, 30, 131-134. [In Chinese, with English abstract]

Liang, G.Y. (1985) Preliminary investigation on horseshoe crab resources in Beibu Gulf. Guangxi Agricultural Sciences, 2, 18-20. [In Chinese]

Liao, Y.Y. \& Li, X.M. (2001) Present situation of horseshoe crab resources in the sea area of China and tactics of preservation. Resources Science, 23, 53-57. [In Chinese, with English abstract]

LiAo, Y.Y. \& Ye, F.L. (2000) Severe depletion of Chinese horseshoe crab resources. China Fisheries, 10, 10-11. [In Chinese]

LiaO, Y.Y., HonG, S.G. \& LI, X.M. (2001) A survey on the horseshoe crabs in the north of South China Sea. Acta Zoologica Sinica, 47, 108-111. [In Chinese, with English abstract]

LiaO, Y.Y., LiU, J.X. \& Zhou, M.W. (2012) Accident and preventive countermeasure of poisoning of eating horseshoe crab in China. Modern Preventive Medicine, 39, 4725-4728. [In Chinese, with English abstract]

NAsh, H.C., Wong, M.H.G. \& Turvey, S.T. (2016) Using local ecological knowledge to determine status and threats of the Critically Endangered Chinese pangolin (Manis pentadactyla) in Hainan, China. Biological Conservation, 196, 189-195.

Pan, Y., Wei, G., Cunningham, A.A., Li, S., Chen, S., Milner-Gulland, E.J. \& Turvey, S.T. (2016) Using local ecological knowledge to assess the status of the Critically Endangered Chinese giant salamander Andrias davidianus in Guizhou Province, China. Oryx, 50, 257-264. 
Rochet, M.J., Prigent, M., Bertrand, J.A., Carpentier, A., Coppin, F., Delpech, J.-P. et al. (2008) Ecosystem trends: evidence for agreement between fishers' perceptions and scientific information. ICES Journal of Marine Science, 65, 1057-1068.

Segan, D.B., Bottrill, M.C., Baxter, P.W.J. \& Possingham, H.P. (2011) Using conservation evidence to guide management. Conservation Biology, 25, 200-202.

Seino, S., Uda, T., Tsuchiya, Y. \& Tsuchiya, K. (2003) Conservation history of horseshoe crab Tachypleus tridentatus and its spawning ground, a designated natural monument in Kasaoka Bay in Okayama Prefecture. Asian and Pacific Coasts, 18, 551-556.

SeKIGUCHI, K. (1988) Biology of Horseshoe Crabs, 1st edition. Science House Co. Ltd., Tokyo, Japan.

Shin, P.K.S., Li, H.Y. \& Cheung, S.G. (2009) Horseshoe crabs in Hong Kong: current population status and human exploitation. In Biology and Conservation of Horseshoe Crabs (eds J.T. Tanacredi, M. L. Botton \& D.R. Smith), pp. 347-36o. Springer US, New York, USA.

Shumway, S.E. (1995) Phycotoxin-related shellfish poisoning: bivalve molluscs are not the only vectors. Reviews in Fisheries Science, 3 , 1-31.

Smith, D.R., Brockmann, H.J., Beekey, M.A., King, T.L., Millard, M.J. \& Zaldivar-RAE, J. (2017) Conservation status of the American horseshoe crab, (Limulus polyphemus): a regional assessment. Reviews in Fish Biology and Fisheries, 27, 135-175.

Surowiecki, J. (2004) The Wisdom of Crowds: Why the Many Are Smarter Than the Few. Little Brown, London, UK.

Turvey, S.T., Risley, C.L., Moore, J.E., Barrett, L.A., Hao, Y., ZHAO, X. et al. (2013) Can local ecological knowledge be used to assess status and extinction drivers in a threatened freshwater cetacean? Biological Conservation, 157, 352-360.

Turvey, S.T., Trung, C.T., Quyet, V.D., Nhu, H.V., Thoai, D.V., TUAN, V.C.A. et al. (2015) Interview-based sighting histories can inform regional conservation prioritization for highly threatened cryptic species. Journal of Applied Ecology, 52, 422-433.

Walls, E.A., Berkson, J. \& Smith, S.A. (2002) The horseshoe crab, Limulus polyphemus: 200 million years of existence, 100 years of study. Reviews in Fisheries Science, 10, 39-73.
WCMC (World Conservation Monitoring Centre) (1996a) Tachypleus tridentatus. In The IUCN Red List of Threatened Species 1996: e.T21309A9267047. Http://dx.doi.org/10.2305/IUCN.UK.1996. RLTS.T21309A9267047.en [accessed 25 May 2017].

WCMC (World Conservation Monitoring Centre) (1996b) Carcinoscorpius rotundicauda. In The IUCN Red List of Threatened Species 1996: e.T3856A10123044. Http://dx.doi.org/10.2305/IUCN. UK.1996.RLTS.T3856A10123044.en [accessed 25 May 2017].

WenG, Z.H., XIE, Y.J., XIAO, Z.Q., HuAnG, L.M., LI, J., WANG, S.H. \& ZHANG, Y.Z. (2012) Distribution and resource of Chinese horseshoe crab (Tachypleus tridentatus) in Fujian and other coast water of China. Chinese Journal of Zoology, 47, 40-48. [In Chinese with English abstract]

Whitmore, N. (2016) Harnessing local ecological knowledge for conservation decision making via Wisdom of Crowds: the case of the Manus green tree snail Papustyla pulcherrima. Oryx, 50, 684-692.

YU, Y. \& MU, Y. (2006) The new institutional arrangements for fisheries management in Beibu Gulf. Marine Policy, 30, 249-26o.

\section{Biographical sketches}

Y. LIAO studies the population biology of Asian horseshoe crabs in Southern China. H. L. HsieH and C. P. CHEN work on habitat conservation and population restocking of Chinese horseshoe crabs in Taiwan and Southern China. S. XU, Q. Zhong, J. LeI, M. LIANG, H. FANG and L. XU conduct ecological studies of Chinese white dolphins, mangroves and fishery resources along the shores of Beibu Gulf in Guangxi, China. W. LIN and X. XIAO are involved in mobilizing local community participation in horseshoe crab and migratory bird conservation. S.G. CHEUNG participates in research and education outreach projects on the conservation of horseshoe crabs in Hong Kong. B. K. Y. KWAN is interested in studying how ecological and social information facilitates wildlife conservation, with a particular focus on conservation of Chinese horseshoe crabs. 